\title{
O FENÔMENO DA DISTOPIA NO CONTO «VERDE», DE RUBEN A.
}

\author{
Marcelo Pacheco Soares*
}

O conto «Verde», escrito por Ruben Alfredo Andresen Leitão (ou Ruben A., pseudônimo com que se notabilizou), encerra o volume Cores, único livro de narrativas curtas do autor, publicado originalmente em 1960. A obra traz oito textos, todos sob o título de uma cor distinta, dentre as quais surgem algumas de natureza mais realista, mas outras, e a maior parte delas, de teor fantástico, o que, de certa maneira, corrobora a relação que a crítica comumente estabelece entre Ruben A. e a estética dos movimentos surrealistas de Portugal. Vale dizer que, em sua pesquisa sobre o assunto, Maria de Fátima MARINHO aloca o autor entre aqueles que ela considera à margem do surrealismo ortodoxo, ou seja, um dos que, «embora nunca tendo feito parte de nenhum dos grupos, apresenta inequivocamente influências e características surrealistas» (MARINHO, 1987, p. 249). Todavia, «Verde» - em que se descreve uma população que vaga por Lisboa comandada por um sistema de teleguiamento via antenas, o que denuncia uma sociedade que se submete a determinadas formas de manipulação e o abandono de uma deambulação crítica pela cidade em troca de uma errância influenciada / conduzida despoticamente por terceiros, que ditam os caminhos a serem percorridos - flerta mais proximamente não com o surrealismo mas com o modo de narrar da ficção científica.

Dizemos que tão somente flerta com o gênero porque, realmente, o conto não apresenta de forma explícita nenhuma evidência que o datasse em uma sociedade futura à sua escrita, como acontece a uma parte considerável das obras identificadas sob essa classificação. O principal traço semântico, não a indicar claramente, mas a tão somente sugerir o aspecto futurista da narrativa, residiria, em termos metafóricos, na própria simbologia que a cor-título classicamente abriga e que é vastamente referida em "Verde»: a esperança, disposição do espírito que sempre projeta suas referências para um futuro (tempo afinal que se espera, recuperando o sentido etimológico do vocábulo). A partir de tal leitura, será possível reconhecer nesse controle robotizado da população - assunto por si futurista

\footnotetext{
* Doutor e Mestre em Literatura Portuguesa pela UFRJ e Professor de Língua Portuguesa e Literatura do IFRJ, promove pesquisa a respeito de contos fantásticos portugueses do último século pouco contemplados pela crítica literária.
} 
— um mote que dialoga com uma série de manifestações artísticas que, de maneira genuína e de forma mais evidente que o texto de Ruben A., se enquadrariam na esfera da ficção científica.

\section{As ficções distópicas}

Quando, no fim da década de 1920, o editor americano Hugo Gernsback cunhou o termo science fiction em revista criada por ele para se dedicar ao gênero, procurava um rótulo que abrangesse algumas obras que, no século XIX, nasciam sob a influência dos avanços tecnológicos, lidando com a ciência como leitmotiv dos enredos nelas desenvolvidos. Desse modo, os romances baseados em pesquisas científicas então atuais, como os de Júlio Verne, por exemplo, os de cunho mais fantasioso, como de W. G. Wells, e também o próprio Frankenstein de Mary Shelley, que precede a todos, poderiam ser etiquetados, mais ou menos pioneiramente, sob essa denominação. Nossa atenção aqui se restringe ao comportamento de obras do gênero que possuam natureza futurista, isto é, que proponham a construção de um hipotético porvir abalizadas, contudo, por elementos do tempo presente.

Essa ficção científica designadamente ambientada em um futuro exibe, via de regra, um mecanismo de composição em que se imagina um amanhã no qual demandas da sociedade contemporânea encontrem-se hiperbolizadas. Quando tais questões levantadas são de caráter negativo (como será muito frequente no século Xx), a crítica comumente reconhece que se está diante de uma distopia (em oposição diametral à Utopia de Thomas Morus), que consiste em uma visão pessimista a respeito do futuro. É o pensador alemão Erich Fromm quem, em posfácio a uma edição de 1961 do romance 1984 de George Orwell, formaliza uma análise geral quanto ao contexto histórico em que germinam as utopias negativas da literatura do século Xx. Nesse artigo, Fromm trata de uma trilogia composta por Nós, editado em 1924, de autoria do russo antissocialista Yevgeny Zamyatin (livro proibido em seu país de origem até 1988, por motivos óbvios) e Admirável novo mundo de Aldous Huxley, de 1932, além do romance do próprio Orwell (publicado em 1949, mas cuja escrita findara em 1948, o que permitiria supor que a eleição do tempo em que se passa o enredo futurístico da narrativa - e consequentemente a escolha do título do livro - tenha sido pensada não aleatoriamente ou com base em concretas predições, mas a partir de uma inversão dos dois algarismos finais do seu ano de produção). Essa trilogia estaria opostamente posicionada a outra, a das utopias positivas dos séculos XVI e XVII, constituída pela obra de Morus a que se somam A cidade do sol de Tommaso Campanella e Cristianópolis de Johann Valentin Andreae. Para Fromm, o marco do fim da esperança na perfeição individual e social do homem (que permeara o 
pós-medievo), quiçá causa primeva de tais distopias literárias mais recentes, teria sido a Primeira Guerra Mundial1 ${ }^{1}$ :

Essa guerra, na qual milhões morreram pelas ambições territoriais das potências europeias, ainda que sob a ilusão de estarem lutando pela paz e pela democracia, foi o início do desenvolvimento que levou, num tempo relativamente curto, à destruição da tradição ocidental de esperança, que contava dois mil anos de idade, e a sua transformação num sentimento de desespero. A insensibilidade moral da Primeira Guerra Mundial foi apenas o começo. Outros eventos se seguiram: a traição das esperanças socialistas pelo capitalismo estatal de $\operatorname{Stalin}^{2}$; a grave crise econômica do fim da década de 1920; a vitória da barbárie em um dos mais antigos centros culturais do mundo - a Alemanha; a insanidade do terror stanilista durante a década de 1930; a Segunda Guerra Mundial, na qual todas as nações em conflito perderam algumas das considerações morais que ainda existiam na Primeira Guerra Mundial; a destruição ilimitada de populações civis, iniciada por Hitler e que teve sequência na destruição ainda mais total de cidades como Hamburgo, Dresden e Tóquio, e, por fim, na utilização de bombas atômicas contra o Japão. (Fromm, 2010, pp. 367-368)

Tais utopias negativas descobrirão também no cinema grande alternativa de expressão, gerando produções como Alphaville (1965) de Jean-Luc Godard, além de O planeta dos macacos (1968) de Franklin J. Schaffner (obra que se confessa uma distopia apenas em sua última cena, o que configura o final-surpresa que lhe dá fama) e 2001: uma odisseia no espaço (1968) de Stanley Kubrick - que apostaria ainda no gênero em Laranja mecânica (1971) — sendo digno de nota também, mesmo mais à frente, Blade Runner (1982) de Ridley Scott, exemplos significativos cujas linhagens convergem ao filme mudo, marco do expressionismo alemão, Metropolis (1927) de Fritz Lang. Poderíamos lembrar, por fim, o romance de Ray Bradbury, de 1953, Fahrenheit 451, homonimamente adaptado para o cinema por François Truffaut (1966). Ora, vem a propósito observar que a concentração dessas produções precisamente nos anos de 1960 é sintoma de um contexto — saldo, aliás, da sequência de fatores inventariados por Fromm - que torna

${ }^{1}$ Erich Fromm, a despeito da linearidade histórica, acresce em nota a obra O tacão de ferro de Jack London, de 1908, como outro exemplo de narrativa distópica. No romance, produz-se a respeito do cenário da luta proletária do início do século XX a visão de homens pertencentes a uma sociedade futura na qual o capitalismo não mais existe. A existência desse livro, porém, não é suficiente para deslegitimar os eventos históricos citados pelo psicanalista alemão como catalisadores da produção dos textos pertencentes à trilogia proposta.

2 O romance de 1905, Uma utopia moderna, de W. G. Wells, ratificaria os argumentos de Fromm, já que sua criação, em que se descreve positivamente uma sociedade baseada na tecnologia e na forte presença do Estado em seu controle, somente é possível antes da decepção do seu autor com a implantação do governo soviético após a Revolução Russa, anos mais tarde por ele dito corrupto. 
propício o aparecimento de obras desse viés e no qual diríamos que o conto «Verde», de Ruben A., publicado logo no início da década, também já estaria mergulhado ${ }^{3}$.

A respeito de tudo isso, é preciso dizer, porém, que o fundamental das distopias futuristas reside menos na capacidade de antever o amanhã de forma precisa (conforme equivocadamente apregoariam os leitores mais incautos) do que no pretexto com que esse fictício distanciamento temporal municia o registro de uma crítica sobre a conjuntura que lhe é atual. Assim, imaginando um plano cartesiano onde o eixo horizontal representasse a variável tempo e o vertical a variável problema (geralmente de ordem social e/ou política e de caráter urbano, muitas vezes ligado a temas como o controle, a vigilância e a opressão do Estado ou de elites detentoras de poder sobre a população em geral, além da desumanização de cidadãos que não podem mais nem mesmo escolher fazer escolhas) e se marcassem, nesse plano, com facilidade os pontos referentes ao passado e o relativo ao presente no gráfico, gerar-se-ia uma reta, grosso modo e por desvio padrão, ascendente, que faria presumir uma ininterrupta continuidade. A narrativa de fiç̧ão-científica distópica elimina a expectativa de que esse traço gráfico estabeleça uma curva descendente em algum momento e opta por marcar o ponto indicativo de um determinado futuro (mais à direita em relação às abscissas) numa posição sempre superior aos demais (tendo as ordenadas como parâmetro), verticalizando o problema ali representado a um grau excessivo nesse espaço-tempo de um porvir ficcional que ambientará a narrativa. Ora, isso não se dá porque seja realística e calculadamente improvável que tal questão se amaine, influenciada que poderia ser por fatores quaisquer, mas antes porque a descrição dessa sociedade futura, a sofrer problemas caricaturalmente majorados, sói suscitar uma reflexão a respeito de alguma demanda que na contemporaneidade de sua produção não causaria $o$ impacto que talvez merecesse, por uma espécie de invisibilidade que ocorre

${ }^{3}$ Uma listagem que se estendesse para além desses títulos cinematográficos seria desnecessariamente exaustiva, embora indubitavelmente volumosa. Aliás, em função disso, os traços principais do gênero, na medida em que foram muito exercitados, cristalizaram-se a ponto de se tornarem de execução relativamente fácil e poderem ser empregados, culminantemente, em películas como, por exemplo, Jogos vorazes (2012), de Gary Ross, onde o funcionamento da técnica narrativa do gênero, tanto no cinema como na literatura onde surge o conjunto de livros de Suzanne Collins que inspiraram o filme, está de tal modo internalizado pelo público que é possível fazer o seu uso em uma obra voltada de modo mais particular para um público leitor / espectador mais identificado com o juvenil e, ademais, sem que se teçam tantas explicações sobre os meandros de sua diegese, como parecia importante nas películas mais antigas que citamos. Prova, aliás, de que o gênero já fora bastante desenvolvido nos anos de 1960 é que no início da década seguinte já seria admissível que se fomentasse ao menos uma produção paródica - O dorminhoco (1973), de Woody Allen - cujos efeitos de humor, para alcançarem sucesso, carecem de que o público identifique os substratos que originam o pastiche. 
justamente por se encontrar em níveis supostamente toleráveis para a coletividade, a qual não se dá conta dos prejuízos a que se encontra efetivamente sujeita. Tal vertente da ficção-científica possui, portanto, a habilidade formal de trazer à luz de modo evidente problemas que na sociedade presente se naturalizaram.

Fromm prossegue o seu raciocínio, o qual claramente corroboramos, no que toca a certa superfluidade do suposto caráter profético de que tal qualidade de escrita gozaria:

As utopias negativas expressam o sentimento de impotência e desesperança do homem moderno assim como as utopias antigas expressavam o sentimento de autoconfiança e esperança do homem pós-medieval. Não poderia haver nada mais paradoxal em termos históricos do que essa mudança: o homem, no início da era industrial, quando na realidade não possuía os recursos para um mundo no qual a mesa estaria posta para todos os que desejassem comer, [...] era repleto de esperança. Quatrocentos anos mais tarde, quando todas essas esperanças são realizáveis, quando o homem pode produzir o suficiente para todos, [...] no momento exato em que o homem está prestes a poder concretizar sua esperança, ele começa a perdê-la. É questão essencial para as três utopias negativas não apenas descrever o futuro rumo ao qual nos movemos como também explicar o paradoxo histórico. (Fromm, 2010, p. 369)

A maioria dessas obras de ficção discute o controle exercido sobre as massas pela ação de governos (ou elites detentoras do poder) que, frequentemente, intervêm no privado - fruto de alguma forma inesperado (paradoxal, como afirmara Fromm) de um modelo capitalista que estabelece suas bases em significativo desenvolvimento tecnológico e científico. As distopias futuristas são, portanto, narrativas que delineiam regimes totalitaristas e sociedades compostas por cidadãos que, ao passo em que teriam relativamente (e sabemos o quanto isso não é, em escala mundial, verdadeiro) sanado as suas necessidades básicas, desenvolveram também metodologias e um arsenal de instrumentos que sofisticaram as suas formas de exercício de poder. Tais romances, portanto, voltam-se fundamentalmente contra as chamadas sociedades de controle.

Tal modelo de organização e funcionamento social, filho do século XX, é descrito por Gilles Deleuze como aquele que, mais contemporaneamente, começou a substituir as sociedades disciplinares (e tal fenômeno substitutivo encontra-se ainda hoje em processo), as mesmas que seu concidadão francês, Michael Foucault, pesquisador assíduo das estratégias e da natureza do poder, identificara pouco antes como marca da modernidade. Por sociedade disciplinar, entende-se aquela baseada em espaços de confinamento, estruturada entre os séculos XVIII e XIX, como esclarece Deleuze em artigo de 1990 em que refere Foucault:

O indivíduo não cessa de passar de um espaço fechado a outro, cada um com suas leis: primeiro a família, depois a escola («você não está mais na família»), 
depois a caserna («você não está mais na escola»), depois a fábrica, de vez em quando o hospital, eventualmente a prisão, que é o meio de confinamento por excelência. [...] Foucault analisou muito bem o projeto ideal de confinamento, visível especialmente na fábrica: concentrar; distribuir no espaço; ordenar no tempo; compor no espaço-tempo uma força produtiva cujo efeito deve ser superior à soma das forças elementares. (DELEUZE, 2000, p. 219)

A partir do século XX, mecanismos diversos permitem que o ato de vigiar o cidadão ultrapasse os muros desses espaços confinados e estenda-se para toda a cidade, toda a sociedade, dos locais públicos aos privados, em uma ação que torna inclusive o próprio homem um guardião de si mesmo, o que amplia as antigas limitações de uma vigilância que estivesse delegada tão somente às instituições: família, escola, trabalho... Ainda segundo Deleuze, controle é, significativamente, o que «Foucault reconhece como nosso futuro próximo» (Deleuze, 2000, p. 220) - e é nesse sentido que estas distopias pós-Primeira Guerra encontram na observação irrestrita por um Big Brother, por exemplo (esse Grande Irmão que tudo observa), uma matéria comum, já que quase invariavelmente desenham esse futuro próximo foucaultiano em que a sociedade de controle se estabeleceu plenamente.

Ao descrever as sociedades disciplinares, Foucault usara o exemplo do Panóptico de Jeremy Bentham, jurista inglês de fins do século XVIII que desenhou um projeto de penitenciária no qual, de uma torre central, seria possível vigiar todas as celas sem que a sentinela fosse vista (sem que mesmo fosse possível saber quando a torre estaria ou não de fato ocupada, gerando um efeito de introjeção do poder no vigiado, que, por isso, autocensura-se, instaurando o poder disciplinador que Foucault apresentara):

O princípio é conhecido: na periferia uma construção em anel; no centro, uma torre: esta é vazada de largas janelas que se abrem sobre a face interna do anel; a construção periférica é dividida em celas, cada uma atravessando toda a espessura da construção; elas têm duas janelas, uma para o interior, correspondendo às janelas da torre; outra, que dá para o exterior, permite que a luz atravesse a cela de lado a lado. Basta então colocar um vigia na torre central, e em cada cela trancar um louco, um doente, um condenado, um operário ou um escolar. Pelo efeito da contraluz, pode-se perceber da torre, recortando-se exatamente sobre a claridade, as pequenas silhuetas cativas nas celas da periferia. Tantas jaulas, tantos pequenos teatros, em que cada ator está sozinho, perfeitamente individualizado e constantemente visível. O dispositivo panóptico organiza unidades espaciais que permitem ver sem parar e reconhecer imediatamente. Em suma, o princípio da masmorra é invertido; ou antes, de suas três funções - trancar, privar de luz e esconder - só se conserva a primeira e suprimem-se as outras duas. A plena luz e o olhar de um vigia captam melhor que a sombra, que finalmente protegia. A visibilidade é uma armadilha. (FoUCAULT, 2009, p. 190) 
Já em uma sociedade de controle, o panoptismo desenvolveu-se junto a tecnologias que lhe permitem prescindir também desse trancamento (Bauman, por exemplo, refere-se a isso como «a armazenagem de quantidades maciças de dados, ampliadas a cada uso de um cartão de crédito e virtualmente a cada ato de compra» resultando "num "superpanóptico"» (BAUMAN, 2000, p. 57). Assim, o uso do desenvolvimento tecnológico para o estabelecimento de tal controle torna-se uma combinação fértil para instituir o paradoxo levantado por Fromm, que mostra como o progresso do homem pode-se voltar contra ele, produzindo a criação desses futuros distópicos que a arte busca representar para encontrar, no presente, as suas causas.

\section{$\mathrm{O}$ «Verde» da desesperança}

Pois tal controle das massas é o tema latente de «Verde», é o seu problema majorado e caricaturado no motivo dos homens teleguiados. O conto de Ruben A. também é uma distopia (distopia inserida em um contexto em que já ocorreram integralmente as motivações previstas por Fromm para o surgimento dessas narrativas, distopia potencialmente influenciada também pelas obras mencionadas de Zamyatin, Huxley, Orwell e Bradbury, todas publicadas anteriormente, nas décadas de 1920, 1930, 1940 e 1950, respectivamente, enquanto Cores abre a de 1960), não obstante o seu aspecto de ambientação futura estar relegado à sugestão trazida pelo próprio argumento do conto e pela explicitada metáfora fornecida pela cor que intitula o texto (simbolismo verde $=$ esperança, que no conto toma valor inaudito de uma alegoria no tom das águas do rio Tejo). Aliás, reparemos que mesmo a referência à esperança, que lemos como sinalização para um futuro, se oferece ali pela via negativa, como uma ficção inalcançável, uma utopia agora impossível, eivada de pessimismo e ceticismo, evidenciando o aspecto distópico do conto, como se pode intuir textualmente: Realmente por que estaria assim o Tejo tão verde, tão esperançoso? - contesta o narrador. O sentimento de esperança que se tematiza surge, então, como explícita manifestação da esperança perdida do homem moderno, identificada por Erich Fromm nas utopias negativas que ele analisou, e que no texto de Ruben A. está concentrada nessa alegoria do Tejo (onde a mancha verde mais carregada alimentava-se num futuro cheio de entusiasmo) e é por isso mesmo que os homens são levados, contra as suas vontades, quando ainda as há, a se afastarem de seu leito, conduzidos pelo teleguiamento.

Para além, no entanto, dessa dupla de dados a indiciar um tempo narrativo futurista em «Verde», é significativo que nenhum outro traço abasteça a hipótese de que o conto se ambiente em um espaço ficcional vindouro. Será, aliás, irônico que o seu período inicial apresente a marca gramatical de um acontecimento passado, ainda que a diferença temporal entre a diegese e o espaço-tempo do narrador 
fosse insignificante do ponto de vista físico (não o sendo, porém, do ponto de vista ideológico): Foi gratuitamente e por acaso que estando ontem na Ribeira das Naus a olhar para um Tejo verde me espantei a trouxe-mouxe. Ora, a cidade descrita no conto se assemelha ao espaço urbano da capital portuguesa contemporâneo à sua produção, desde os barcos catraeiros e as velhas fragatas a deslizarem sobre as águas do Tejo observados a partir da Ribeira das Naus até os eléctricos de Lisboa, que viveram o auge do seu funcionamento e alcance justamente em fins da década de 1950, quando percorriam mais de cento e cinquenta quilômetros pela cidade. Somam-se a isso os cenários descritos da região mais marginal de Lisboa, como o Poço do Bispo e Moscavide, ou ainda o Terreiro do Paço, a Rua dos Correeiros, a Rua do Ouro, o Rossio ou o Teatro Nacional, onde os personagens são levados, nessa ordem, a caminhar por longas horas, gratuitamente e em círculos como sugerem os pontos de referência descritos, até alcançarem a Avenida da Liberdade, quando peregrinarão em direção ao único elemento urbano que inviabiliza o seu mimetismo com a Lisboa real. Trata-se da Torre de Comando Teleguiadora - panóptico benthamiano referido por Foucault, peça que controla a liberdade irreal do cidadão (e é por completa ironia que esteja localizada no alto de uma avenida que leva esse nome), a liberdade vigiada e aqui, mais do que isso, deliberadamente manipulada, a ocupar, como sabemos, o espaço da estátua do déspota esclarecido português - o Marquês de Pombal.

Esse cenário hodierno parece servir de intencional recurso para que, a partir de um argumento (e quiçá não propriamente de uma ambientação) futurista daí, então, que se estabeleça a ironia de descrever esse espaço forjadamente futuro em um discurso que remeta ao passado recente, expresso na localização temporal assinalada pelo advérbio ontem do período inicial do conto - para que, repito, Ruben A. discuta e apresente, sob a égide de um contexto fantástico que é o controle remoto dos movimentos dos cidadãos, a sociedade lisboeta (e certamente a ocidental de forma geral) não precisamente do futuro, mas a do seu próprio tempo - em coadunação com a função principal que levantamos para as distopias: a de produzir crítica a respeito do tempo presente — pintando-nos, sob a representatividade literária, essa sociedade de controle que Deleuze identificaria e sobre a qual teorizaria décadas mais tarde, a partir das considerações tecidas por Foucault.

A razão de, no conto de Ruben A., tal controle acontecer por intermédio de um sistema de antenas poderia remeter às transmissões televisivas e radiofônicas, que já em 1960 dividiam o alcance das massas e figuravam como importantes instrumentos de formação de opinião - e, mesmo ultrapassando a metáfora, é digno de nota que também a leitura da mídia impressa é controlada pelas mesmas forças oriundas da torre de comando central (haja vista que passageiros do bonde liam os jornais teleguiados). Trata-se, pois, de uma torre antibabélica que violentamente obriga todos a falarem a mesma língua ou, para sermos mais precisos, a seguirem os mesmos caminhos. O que Lucrécia Ferrara ressalta quatro décadas mais tarde 
já era, então, guardadas é claro as devidas proporções, observável no ambiente em que nasce «Verde»:

De certa forma, a cidade dos nossos dias vive o impacto crescente dos veículos de comunicação e informação que, se de um lado, são responsáveis por uma civilização que se globaliza pela possibilidade de criar e propagar a informação minimizando tempos e diferenças; de outro, transforma a vida urbana na imagem padrão que unifica todos os espaços públicos e privados. O imaginário transforma-se na imagem que corrige o particular indeterminado, adaptando-o ao padrão comum e geral. (FERRARA, 2000, p. 130)

Ora, a citada torre de comando, sobre a qual não se esclarece se quem de fato a controla seria o governo ou outra qualquer organização representante do poder, é antes, de certa maneira, uma espécie de referência abstrata ao controle deleuziano que se institui nas sociedades modernas do que uma entidade ou grupo operacional real contra o qual os cidadãos poderiam se rebelar. Essa torre é o inimigo invisível e diluído na sociedade, manifestado, por exemplo, na burocracia; e não é por acaso que a figura do chefe de repartição assuma igualmente a de chefe do grupo que deambula forçadamente por Lisboa em «Verde» sob os comandos da torre de controle. Essa torre é, aliás, a disciplina introjetada que Foucault descobre no panoptismo, internalizada pelos membros da sociedade por ela vigiada e que lhes afasta do verde da esperança que matiza o Tejo, em cujo fundo ela está ocultada / protegida e de onde, por isso, os personagens são, como já destacamos, estrategicamente afastados.

Esse rio, com seus reflexos esverdeados, surge aqui também como símbolo da própria narrativa ficcional, notadamente a fantástica: é sob os seus tons esverdeados que a narrativa se desenvolve, na cidade refletida no espelho d'água, a indiciar o aspecto insólito em que seu enredo se processa. Evidencia-se então a literatura como uma criação baseada no mundo empírico, ainda que a narração pertença a um gênero irrealista: a imagem refletida em verde não é autêntica, possuindo porém o seu substrato real — isto é, a Lisboa fantástica, que se observa sob os tons verdes do rio, é um reflexo possível (artístico-literário) da Lisboa real. O Tejo encontra-se, desse modo, constituído por uma água verde a espelhar-se contra os barcos, verde que mais à frente será, como antecipamos, associado ao futuro (Eu olhava para as bandas lá do fundo e a mancha verde mais carregada alimentava-se num futuro cheio de entusiasmo.) e à esperança (Em todos havia uma esperança a olhar para aquele verde nem tremendo nem trágico.).

Essa esperança reside numa expectativa de fuga da opressão da cidade e do seu governo totalitarista; e é inescapável que lembremos que sua escritura ocorre no auge do regime salazarista, que, aliás, marcou a arquitetura citadina com o levantamento de «torres de vigia, que ainda subsistem um pouco por todo o país nas imediações de estruturas militares ou outros recintos do estado, [...] vestígios 
menos polidos dessa preocupação evidente do longo braço do governo no estabelecimento de mecanismos físicos de controlo» (SiLva, 2007, p. 157). Ao que parece, porém, essa evasão desejada pelo herói é inalcançável: A esperança era diminuta - não se podia fugir a ser teleguiado. A cidade é a prisão panóptica que Deleuze entendera ultrapassar os muros da instituição concreta para se institucionalizar por toda a sociedade.

Por isso, a partir de uma demonização do espaço urbano - descrito de forma decadente, desde as velas rotas e remendadas das velhas fragatas a levarem ninharias pelo Tejo até uns cachorros rabujentos a lamberem a babugem mais fácil, passando pelo man piso habitual das ruas da cidade e pelas coisas feias e dejetas a boiarem no verde límpido do rio - faz-se apologia à evasão para locais não centrais: O fim de abril chamava para uma liberdade em férias de praia ou campo. Há-de se destacar, nesse sentido, a insistentemente referida professora de instrução primária conhecida do protagonista, a qual vive no meio rural, cuja beleza virgem encontra nas personagens urbanas representadas por duas senhoras da Império (cheias de peles, pinturas fora do lugar, berliques e berloques falsos e bunda avantajada e com seus dedos pavorosos de pequenas elevações calosas e a barriga a sair pelas bermas de uma cinta calmeirona) um mais absoluto contraste.

Daí que o personagem, em sua narração, faça referência a «O sentimento de um ocidental», de Cesário Verde - quiçá o maior exemplo de flânerie da poesia portuguesa, encontrando par talvez apenas nas lisboas revisitadas por Fernando Pessoa - e precisamente ao trecho que trata da soturnidade e da melancolia que há nas ruas, ao anoitecer, despertando um desejo absurdo de sofrer, contrapondo-o ao verso que afirma que os que se vão partem felizes. É notório, aliás, que o conto remonta, em traços diversos, ao poema oitocentista - o que lega, evidentemente, novo significado à alusão ao verde que lhe intitula. Cá está o protagonista, como o poeta Verde do século XIX, próximo ao Tejo de uma mesma Lisboa, em um fim de tarde, encarando o espaço urbano sob semelhante melancolia. Cá está ele enquanto táxis se raspavam em bumbas de susto para as várias estações marginais, tal como, no poema, batem os carros d'aluguer, ao fundo. E eis que surgem, no caminho que logo a seguir ele empreenderá, personagens que representam classes diversas das castas urbanas, como ocorre no poema de Cesário (com dentistas, donas-de-casa, bêbados, lojistas, padres, floristas, soldados e prostitutas): amanuenses de Juntas, Ministérios e Grémios, chefe de repartição, além dos personagens com evidente função fabulista (por serem animais que representam os homens) - o burro e o papagaio - e, por fim, as aludidas duas senhoras frequentadoras da Império, cuja referência ao estabelecimento que frequentam evidentemente se refere ao tempo monárquico de Cesário Verde, que, todavia, segundo se sabe, era republicano. 
Mas a República com que sonhara o poeta realista transformara-se no Estado Novo de Salazar, fator que coloca em xeque o futuro imaginado por ele e provoca no narrador do conto o efeito de que a esperança se desencante no século que se lhe segue, constatação que o narrador textualiza com mais frequência próximo ao fim do conto: Raio de mundo que tão depressa nos tirou a esperança, o verde fugia de todos nós. / Ninguém olhava para nós - caminhávamos no absurdo sem graça ou esperança. / O verde tinha sido sol de pouca dura. Aquilo de esperanças e poesia era anormalidade. / O mundo coloria-se de saudade do verde. E, quando afinal esse sentimento novamente se projeta (Estávamos ali na esperança de voltar a ver o Tejo verde e um dia seguinte alegre.), é para se desfazer nos dois períodos finais da narrativa: Um novo esticão imobilizou-me encostado ao burro, que mirava espantado os primeiros acordes da manhã. Só para ele o Tejo ainda estava verde. Assim, a figura desse animal que pode ser facilmente guiado (por arreios e por treinamento, por exemplo) surge como a representação evidente do membro da sociedade mais facilmente manipulado (a respeito disso, aliás, o protagonista identifica no animal o único que aceitava a teleguiação passivamente). Também o papagaio merece análise semelhante: seu discurso é sempre reprodução irrefletida (sendo representativo então o fato de que sua primeira aparição se dê precisamente sobre a cabeça do burro). Estamos diante da metaforização do resultado mais radical de uma sociedade cujos membros vivem sob controle. Sem dúvida, seria o burro aquele efetivamente capaz de se crer mais livre enquanto na verdade se afasta de um futuro mais esperançoso: lembremos que subir a Avenida da Liberdade lisboeta, levando em conta que o verbo acena para um crescimento dos números dos endereços, é na verdade, geograficamente, afastar-se do Tejo, em cujo leito metaforicamente a esperança estaria ocultada.

Por isso estamos diante desse cenário de absoluto desencanto, em que então estava tudo frustrado - e no qual podemos encontrar o burro que não zurrava, o papagaio que não podia falar, as senhoras que não tinham amantes e o chefe de repartição que não tinha despacho. A frustração que se processa (e está vinculada à República futura sonhada no século XIX por Cesário Verde e outros que com ele comungavam da mesma ideologia) projeta a felicidade para dias ainda mais vindouros, para um tempo ainda mais futuro. Esse futuro descrito e esperado em «Verde» é, portanto, reiteremos, o futuro do futuro de Cesário; e, se nos for permitido manejar ludicamente as nomenclaturas gramaticais, diríamos que o tempo que o conto afinal reivindica é um futuro mais que perfeito cesariano, superação portanto da perfeição tencionada para um tempo indefinido ainda por derivar. 
Resumo: O artigo promove a leitura do conto «Verde», de Ruben A., publicado em 1960, a partir de um contexto artístico marcado pelo advento das ficções futurísticas distópicas do século Xx e sob conceitos sócio-filosóficos que descrevem as sociedades contemporâneas como espaços de disciplina e controle.

Palavras-chave: Conto português, Ficção-científica, Sociedades de controle.
Abstract: The article promotes the reading of the story «Verde», by Ruben A., published in 1960, from an artistic context marked by the advent of the futuristic dystopian fiction of the twentieth century and considering socio-philosophical concepts that describe contemporary societies as spaces of discipline and control.

Keywords: Portuguese short-story, Science fiction, Control societies.

\section{REFERÊNCIAS BIBLIOGRÁFICAS:}

Allen, Woody. Sleeper. Estados Unidos: 20th Century Fox, 1973 (filme).

AndreAe, Johann Valentin. Christianopolis. Trad., Felix Emil Held. Nova York: Oxford University Press, 1916.

Bauman, Zigmunt. Globalização: consequências humanas. Trad. Marcus Penchel, Rio de Janeiro: Zahar, 2000.

Campanella, Tommasso. A cidade do sol. Trad. Ciro Mioranza, São Paulo: Escala, 2008.

Deleuze, Gilles. «Post-scriptum sobre as sociedades de controle», in Conversações. Trad. Peter Pál Pelbart, Rio de Janeiro: Editora 34, 2000, pp. 219-226.

FERRARA, Lucrecia D’Aléssio. Os significados urbanos. São Paulo: EdUSP, 2000.

FouCAult, Michel. «O panoptismo», in Vigiar e punir. Trad. Raquel Ramalhete, Petrópolis: Vozes, 2009, pp. 186-214.

Fromm, Erich. «Posfácios - Erich Fromm (1961)», in Orwell, George. 1984. Trad. Alexandre Hubner; Heloisa Jahn, São Paulo: Companhia das Letras, 2010, pp. 365-379.

GODARD, Jean-Luc. Alphaville. França/Itália: Athos Films, 1965 (filme).

Huxley, Aldous. Admirável mundo novo. Trad., Vidal de Oliveira; Lino Vallandro, Porto Alegre: Globo, 1979.

KUBRICK, Stanley. 2001: a space odyssey. Estados Unidos/Reino Unido: Metro-Goldwyn-Mayer, 1968 (filme).

- A clockwork orange. Reino Unido: Warner Bros. Pictures, 1971 (filme).

LANG, Fritz. Metropolis. Alemanha: Universum Film A. G., 1926 (filme).

London, Jack. O tacão de ferro. Trad. Afonso Teixeira Filho, São Paulo: Boitempo, 2003.

Morus, Thomas. Utopia. Trad. Paulo Neves, Porto Alegre: LPM, 1997.

Orwell, George. 1984. Trad. Alexandre Hubner; Heloisa Jahn, São Paulo: Companhia das Letras, 2010.

Ross, Gary. The hunger games. Estados Unidos: Lionsgate, 2012 (filme).

Ruben A. Cores. Lisboa: Assírio \& Alvim, 1989.

SCHAFFner, Franklin J. Planet of the apes. Estados Unidos: 20th Century Fox, 1968 (filme).

ScotT, Ridley. Blade Runner. Estados Unidos: Columbia Tristar/Warner Bros. Pictures, 1982 (filme).

SILVA, Duarte Nuno Almeida Alves da. Estórias da arquitectura portuguesa - uma reflexão em 
torno de imagens que a arquitectura constrói, o cinema fixa e o povo ordena. Coimbra: UC, 2007.

Truffaut, François. Fahrenheit 451. França/Reino Unido: Anglo Enterprises/Vineyard Film., 1966 (filme).

Verde, Cesário. Obra Completa. Lisboa: Livros Horizonte, 1992.

Welis, H. G. A modern utopia. Londres: Odhams Press, 1908.

YevgenY, Zamyatin. We. Londres: Trafalgar Square, 2009. 
metamorfoses_12.1_Layout 1 12/20/13 4:42 PM Page 120 $\otimes$ 